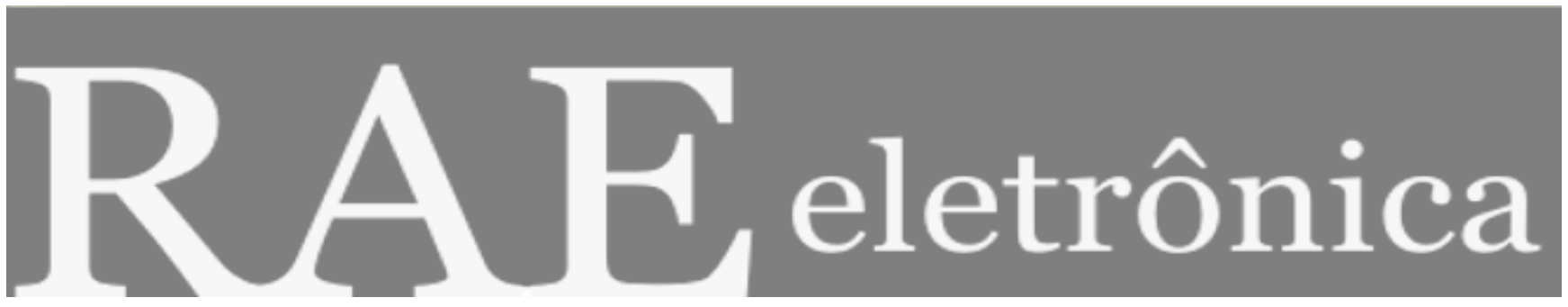

\title{
TECNOLOGIA VERSUS QUALIFICAÇÃO: IMPACTOS NO SETOR DE SAÚDE
}

Por:

Sandra Mara Maciel de Lima

RAE-eletrônica, v. 2, n. 2, jul-dez/2003.

http://www.rae.com.br/eletronica/index.cfm?FuseAction=Artigo\&ID $=1856 \&$ Secao $=$ RECURSOS\&Volume $=2 \& N u m e r o=2$ $\& A n o=2003$

CCopyright, 2002, RAE-eletrônica. Todos os direitos, inclusive de tradução, são reservados. É permitido citar parte de artigos sem autorização prévia desde que seja identificada a fonte. A reprodução total de artigos é proibida. Os artigos só devem ser usados para uso pessoal e nãocomercial. Em caso de dúvidas, consulte a redação: redacao@,rae.com.br.

A RAE-eletrônica é a revista on-line da FGV-EAESP, totalmente aberta e criada com o objetivo de agilizar a veiculação de trabalhos inéditos. Lançada em janeiro de 2002, com perfil acadêmico, é dedicada a professores, pesquisadores e estudantes. Para mais informações consulte o site www.rae.com.br/eletronica.

RAE-eletrônica ISSN 1676-5648

(C)2002 Editora: Fundação Getulio Vargas - Escola de Administração de Empresas de São Paulo.

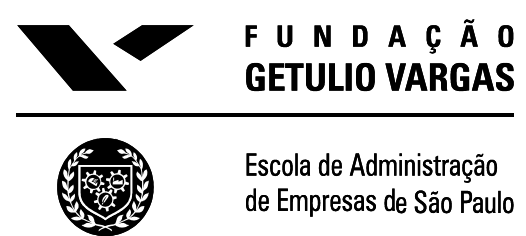




\section{TECNOLOGIA VERSUS QUALIFICAÇÃO: IMPACTOS NO SETOR DE SAÚDE}

\section{Sandra Mara Maciel de Lima}

Bacharel em Ciências Econômicas / Mestre em Administração (UFPR)

E-mail: sandramaciel@avalon.sul.com.br

Endereço: Rua Sargento Lafayette, no 2211 - B1. 7 ap. 102, Bacacheri, Curitiba - PR, 82515-090.

Interesses de Pesquisa: Relações de trabalho, subjetividade, relação entre sociedade e natureza, impactos da tecnologia sobre o trabalho no setor de serviços.

\section{RESUMO}

O presente artigo tem como objetivo analisar os impactos da tecnologia informacional sobre a qualificação dos profissionais de saúde. Apresenta resultado de pesquisa realizada nas unidades de saúde do município de Curitiba, no ano de 2001, envolvendo médicos, enfermeiros e auxiliares de enfermagem. Baseada em pesquisa descritivo-qualitativa, entrevistas e formulários Escala Likert, a análise dos dados demonstra que a aproximação do sistema informacional do sistema de saúde tende a precarizar o trabalho como um todo, perdendo em qualidade e resolutividade. $\mathrm{O}$ trabalho sofre a interferência direta da máquina, e tende a desqualificar o profissional, à medida que o obriga a se familiarizar com um instrumento estranho ao seu próprio trabalho. O texto permite, conduzido pela estratégia dialética utilizada, deslocar o conceito de qualificação de um domínio instrumental para o domínio substantivo.

\section{ABSTRACT}

This text is a result of a search carried out in the health's units of Curitiba, in 2001, involving doctors, nurses and health's assistants. The objective of this text is to analyse the impacts of informational technology over the specific qualification of health's professionals. Based in a descriptive-qualitative research, interviews, Likert form Scale, the analysis of data demonstrates that the approach of the informational system to the health's system turns precarious the work as a whole, loosing in quality and solution. The work is directly affected by the machine and tends to weak the professional obligating him to be familiarized with an unfamiliar instrument to his own work. The text allows, conducted by the dialectic strategy used, to dislocate the concept of qualification from an instrumental dominion to a substantive dominion.

\section{PALAVRAS-CHAVE}

Qualificação; Relações de Trabalho, Tecnologia Informacional, Impactos da Tecnologia, Precarização do Trabalho

\section{KEY-WORDS}

Qualification; Work Relationship; Informational Techonology; Impacts of technology; Precariousness of work. 


\section{INTRODUÇÃO}

Falar dos impactos da tecnologia informacional no setor de saúde implica fazer referência obrigatória ao processo mundial de reestruturação produtiva, intensificado a partir da década de 1970 e suas incursões nos diversos setores da economia.

Por sua vez, a segunda metade dos anos 70 marca um processo irreversível da indústria manufatureira, referente ao deslanchar das novas formas de automação. $\mathrm{Na}$ época podem ser identificados dois fenômenos de importância considerável para esta discussão, a crise do taylorismo e a mutação das normas de concorrência provocada pela crise econômica (Coriat, 1988; Harvey, 1993). Tais fatores provocam e influenciam novas direções às pesquisas em inovação tecnológica (Harnecker, 2000).

Apoiado na rígida separação entre concepção e execução, o taylorismo como estratégia organizacional descreve como a produtividade do trabalho pode ser radicalmente aumentada por meio da decomposição de cada processo de trabalho em movimentos componentes e da organização de tarefas fragmentadas segundo padrões rigorosos de tempo e estudo do movimento (Harvey, 1993).

A introdução das linhas de montagem por Ford estende estas inovações, favorecendo a passagem a um processo de trabalho baseado nos tempos impostos, regulados pelas esteiras mecânicas (Coriat, 1988). No entanto, para outros autoes, o fordismo pode ser considerado como um paradigma que concentra industrialização pesada, organização industrial, processo de trabalho, ideologia e estilo de vida bem determinados.

Leite, por sua vez, identifica três períodos do processo de industrialização. O primeiro corresponde ao final dos anos 70 e início dos 80 , "quando as propostas inovadoras se concentravam na adoção dos CCQs, sem que as empresas se preocupassem em alterar as formas de organização do trabalho ou investir mais efetivamente em novos equipamentos microeletrônicos” (Leite, 1994, p.565).

O segundo período se inicia em 1984-85, a partir da retomada do crescimento econômico (que sucede a profunda recessão dos primeiros anos da década) e vai até o final dos anos 80 , caracterizando-se por uma rápida difusão dos equipamentos industriais. Nesta fase as empresas também buscavam novas formas de organização do trabalho, baseadas sobretudo nas técnicas japonesas. No entanto, "vários estudos enfatizaram o fraco empenho empresarial em inovações organizacionais no período" (Abramo citado por Leite, 1994, p.567). Destaca-se ainda, a resistência que as empresas opuseram a que os trabalhadores pudessem participar dos trabalhos de programação, mantendo dessa forma a separação taylorista entre execução e concepção.

O terceiro período se inicia nos anos 90, contexto no qual as empresas concentravam esforços em estratégias organizacionais, "bem como na adoção de novas formas de gestão da mão-de-obra, mais compatíveis com as necessidades de flexibilização do trabalho e com o envolvimento dos trabalhadores com a qualidade e a produtividade" (Leite, 1994, p.573).

No bojo desta chamada "revolução produtiva" ou "revolução informacional" há transferência, para as máquinas, de um novo tipo de funções cerebrais abstratas (o que propriamente caracteriza a automação), tendo como conseqüência fundamental, o deslocamento do trabalho humano da manipulação para o tratamento de símbolos abstratos - e, pois, deslocá-lo para o tratamento da informação. 
Desta forma, para Lojkine (1995), a revolução informacional nasce da oposição entre a revolução da máquina-ferramenta, fundada na objetivação das funções manuais, e a revolução da automação, baseada na objetivação de certas funções cerebrais desenvolvidas pelo maquinismo industrial.

Sendo assim, cada modo de crescimento do capitalismo estaria configurado pela forma de organização da produção mais adequada para maximizar a rentabilidade das empresas sob cada uma das sucessivas revoluções tecnológicas (Harnecker, 2000). E o que diferencia uma época histórica de outra, conforme Marx, não é o que se faz, mas como, com que meios se faz (Marx, 1988). Ou, como afirma Castells, “o que distingue uma época da outra são a revolução das tecnologias da informação e a sua difusão em todas as esferas da atividade social e econômica [...]” (Castells citado por Harnecker, 2000).

Portanto, para Marx, todo o processo de trabalho se dá inserido em determinadas relações de produção, e que são estas relações que impulsionam o desenvolvimento de determinadas tecnologias (Harnecker, 2000, p. 119).

Da perspectiva das relações de trabalho, as duas experiências históricas, tanto o auge do fordismo quanto a reestruturação produtiva, impactam negativamente sobre o indivíduo. Embora as empresas inovadoras demonstrem estarem preocupadas em treinar seus trabalhadores, a qualificação parece não ser a única preocupação presente nos investimentos empresariais. Na realidade, boa parte dos esforços empresariais voltados para o treinamento, tem como pano de fundo programas comportamentais ou motivacionais, com o objetivo de despertar nos trabalhadores uma postura cooperativa com relação às estratégias gerenciais e que nada tem a ver com formação de trabalhadores mais qualificados (Leite, 1994).

Sendo assim, parece que as novas tecnologias e formas de organização, além de provocarem conseqüências sobre a quantidade de trabalho, também apresentam efeitos sobre a qualidade do mesmo, no que diz respeito à qualificação. "Algumas profissões desaparecem, outras se desenvolvem, ganham importância (...) Isso tudo demonstra que as inovações tecnológicas afetam a qualificação das tarefas desenvolvidas no processo de produção, alterando a própria qualificação exigida do trabalhador" (Dieese, 1994, p. 66).

A desqualificação gerada no auge da organização fordista do trabalho agora é motivo de preocupação. O próprio processo de trabalho - inclusive na saúde - exige maior qualificação em termos tecnológicos do que específicos em termos profissionais. Se em outros setores da vida produtiva contemporânea, profissionais valorizados são os que possuem uma maior intelectualização ou melhor preparo para o trabalho automatizado, no setor de saúde, o que ainda tem valor é a formação específica do profissional. Sem ela, será de pouca valia o domínio do trabalho automatizado.

Seguindo o mesmo raciocínio, a aproximação do sistema técnico informacional do sistema de saúde tende a precarizar o profissional de saúde à medida que exige conhecimento além da natureza do seu trabalho, obrigando-o a se familiarizar com um instrumento estranho ao seu próprio trabalho. Ao ficar mais tempo familiarizando-se, adaptando-se, dando mais atenção à máquina, a tendência é comprometer, degenerar as relações entre os homens. Até porque, não tem como pensar em saúde sem pensar nas relações sociais entre homens.

Em suma, talvez a tecnologia não seja determinante dessas transformações, entretanto, representa um aspecto importante nas modificações ocorridas no processo de trabalho industrial, legitimando, por sua vez, estudos que investiguem tais transformações em outros setores da economia. 


\section{METODOLOGIA}

O presente artigo apresenta resultados de pesquisa desenvolvida no setor de serviços. Um estudo descritivo, que procura analisar os impactos causados pela tecnologia informacional sobre as relações de trabalho e, mais especificamente neste texto, sobre a qualificação específica dos profissionais (médicos, enfermeiros e auxiliares de enfermagem), tomando por base unidades de saúde do município de Curitiba, em que a organização do trabalho foi substituída por atividades sustentadas pela tecnologia de base informacional.

Para tanto, optou-se pela metodologia de estudo de caso utilizando-se diferentes mecanismos de coleta, como questionário estruturado (aplicados pelo pesquisador), entrevistas semi-estruturadas (gravadas e transcritas) e consulta a relatórios da organização. A perspectiva de estudo é longitudinal uma vez que se pretende analisar as categorias descritas num determinado período. $O$ nível de análise é o organizacional e a unidade de análise é constituída pelos profissionais de saúde: médicos, enfermeiros e auxiliares de enfermagem. Nesta perspectiva optou-se em realizar um cruzamento de técnicas qualitativas e quantitativas para a coleta e análise dos dados.

A organização estudada foi escolhida intencionalmente, pelo fato de, no momento da pesquisa, estar implementando o "Acolhimento Solidário" e o Cartão Saúde. Ambos com o objetivo de resolver problemas como morosidade, pouca efetividade e baixa qualidade das ações em saúde.

O Acolhimento Solidário alterou o processo de trabalho no sentido de reorganizar o atendimento, eliminar as barreiras que limitam o acesso ao atendimento, atender prontamente a clientela de risco, eliminar as filas, melhorar a quantidade e a qualidade dos equipamentos utilizados nas unidades de saúde, assim como, estreitar laços com a comunidade local ${ }^{1}$. Um conjunto de procedimentos e técnicas que caracteriza uma mudança em tecnologia de gestão.

Paralelamente ao Acolhimento Solidário, a Secretaria Municipal de Saúde (SMS) implantou uma mudança gradativa em tecnologia física, com a introdução de computadores, de um sistema de gerenciamento informacional, com vistas a aprimorar o atendimento e propiciar um melhor acompanhamento das práticas em saúde. O desenvolvimento e implantação do projeto de informatização na SMS, que agregou o nome de Cartão Saúde, considera pressupostos básicos como:

a) o cadastramento integral da população;

b) utilização de um cartão personalizado para identificação da população cadastrada e para acesso a um prontuário de saúde do seu portador;

c) disponibilização do prontuário de saúde a todas as Unidades de Saúde do município, por intermédio de rede interligada entre as unidades da SMS e entre unidades do Sistema Único de Saúde (SUS);

d) possibilidade de obter, por meio dos prontuários, informações de interesse da saúde e da administração, visando gerar dados para tomada de decisões epidemiológicas, técnicas e gerenciais.

Para desenvolvimento e implantação deste projeto, junto à equipe de informática responsável pelo sistema foi constituído um grupo de trabalho, composto por profissionais da saúde, para acompanhar e auxiliar no desenvolvimento e implantação do sistema informatizado. Este sistema foi elaborado 
tomando-se como base um prontuário médico tradicional e as etapas foram sendo construídas procurando otimizar o processo de atendimento. Para tanto, alguns procedimentos habituais tiveram que se adaptar ao novo processo instituído pelo sistema informatizado, assim como, novas atribuições foram impostas aos profissionais como, por exemplo, o manuseio de computadores e impressoras como ferramenta obrigatória e centralizadora no atendimento ao público.

Este sistema vem sendo implantado gradativamente desde fevereiro de 1999, juntamente com a informatização da rede própria e a adoção do prontuário eletrônico ${ }^{2}$.

Sendo assim, o alvo principal do presente estudo é a opinião dos profissionais de saúde envolvidos no processo de adaptação e implantação do sistema nas unidades de saúde. A população é composta por todos os indivíduos que trabalham na organização, perfazendo um total de 2605 profissionais médicos, auxiliares e enfermeiros ${ }^{3}$.

Devido às características próprias da população de interesse desta pesquisa, optou-se pela amostragem não probabilística por julgamento. Este método é usado quando cada elemento da população possui uma probabilidade desconhecida de seleção, sendo que a amostragem é feita por conveniência, em que os elementos da população são selecionados com base no julgamento do pesquisador (Malhotra, 2001).

A elaboração do formulário contou com a realização de entrevistas exploratórias, aplicadas a auxiliares de enfermagem pertencentes a algumas unidades de saúde do município de Curitiba, no início do ano de 2001. Este formulário utiliza-se de uma escala de classificação por item, inspirada na Escala de Likert, uma escala de classificação amplamente utilizada, exigindo dos entrevistados que indiquem um grau de concordância ou discordância com cada uma de uma série de afirmações. Atribuiu-se a cada afirmação um escore numérico, de 1 (discordância total) a 4 (concordância total), excluindo-se a coluna da neutralidade (Malhotra, 2001).

Realizou-se, então, uma seleção de 30 unidades conforme três critérios básicos: o tempo de informatização na unidade, o tempo de permanência dos funcionários e a distribuição regional das unidades. A aplicação do formulário deu-se de forma aleatória, porém estratificada, de forma a garantir uma composição proporcional entre os profissionais: médicos, enfermeiros e auxiliares.

A pesquisa realizada entre 01 de outubro e 19 de novembro de 2001, portanto, contou com o resultado da aplicação de 265 formulários Escala Likert e de 14 entrevistas semi-estruturadas aos profissionais de saúde, escolhidos de forma aleatória, porém, estratificada, com o objetivo de garantir uma composição proporcional entre médicos, enfermeiros e auxiliares.

A análise dos dados realizou-se por meio de tabelas de distribuição de freqüências, tabelas de tabulação cruzada, também chamadas de tabelas de contingência, sendo que as entrevistas semi-estruturadas foram preparadas e analisadas pela técnica de análise de conteúdo (Bardin, 1979), com o objetivo de identificar e classificar os indicadores obtidos nas mensagens gravadas.

Os resultados, tanto do formulário quanto das entrevistas, estão distribuídos ao longo do texto de forma simultânea, com a intenção de confrontar as percepções dos profissionais e a teoria existente sobre o assunto. Percebe-se em vários momentos que os dados quantitativos mostram-se contraditórios aos depoimentos dos profissionais, resultado de verdadeiros desabafos, revelando a subjetividade deste profissional frente à mudança objetiva do seu trabalho. 
Cabe ainda ressaltar que a estratégia metodológica do artigo está apoiada na dialética, partindo pois do pressuposto de que a teoria usada como referência de análise não é fechada, está sempre passível de reformulações ao longo da pesquisa.

Seguindo essa ordem de idéias, o texto desenvolve o conceito de qualificação abordando "o controle sobre a máquina", "a qualificação polivalente ou politécnica" e por fim "o conhecimento como pilar da qualificação", procurando mostrar que o conceito de qualificação adquiriu sofisticação e pode ser reconstruído, reformulado diante dos resultados da pesquisa. E, por fim, apresentam-se alguns indicadores da precarização do trabalho dos profissionais da saúde no município de Curitiba.

\section{O CONTROLE SOBRE A MÁQUINA}

De acordo com as necessidades das organizações sociais de cada época, ao longo dos anos o conceito de qualificação vem se transformando para atender às referidas demandas. A discussão sobre qualificação engloba não apenas estratégias gerenciais de controle do trabalho e de obtenção de maisvalia, mas também a forma como o trabalhador, o indivíduo percebe e reage a este processo.

$\mathrm{Na}$ década de 30, a noção de qualificação estava vinculada apenas ao controle da maquinaria. Braverman cita o trabalho do Dr. Alba Edwards, no qual os trabalhadores eram classificados entre qualificados - artífices, os não-qualificados - apenas trabalhadores e os semi-qualificados - operários (Braverman, 1987). Na tipologia citada, qualquer atividade não ligada à máquina, era classificada como não-qualificada.

Nesta perspectiva, um trabalhador qualificado seria aquele artífice cujo preparo se deu por vários anos e é formalmente reconhecido fora de uma firma individual; um trabalhador semi-qualificado seria aquele que, durante um curto período de preparo adquiriu a destreza manual ou conhecimento mecânico necessários para a sua função imediata, e um trabalhador não-qualificado aquele cuja função não exige preparo formal algum de qualquer espécie.

Sendo assim, ao se reduzir o trabalho à realização de tarefas parceladas, afasta-se o trabalhador do processo de concepção. Apoiado na rígida separação entre concepção e execução, o taylorismo como estratégia organizacional descreve como a produtividade do trabalho pode ser radicalmente aumentada por meio da decomposição de cada processo de trabalho em movimentos componentes e da organização de tarefas fragmentadas em conformidade com padrões rigorosos de tempo e estudo do movimento (Harvey, 1993). O trabalho de um marceneiro, por exemplo, embora necessite de muita experiência e criatividade para criar e produzir um determinado objeto, deixa de ser caracterizado como trabalho qualificado.

$\mathrm{Na}$ perspectiva do trabalhador, o conceito de qualificação está ligado ao domínio do ofício, à combinação de conhecimento de materiais e processos com as habilidades manuais exigidas para $o$ desempenho de determinada função.

Com o parcelamento das funções e a reconstrução da produção como processo coletivo ou social (Braverman, 1987), qualificação passou a ser interpretada como habilidade específica, operação limitada e repetitiva. Qualificação passa a ser confundida com destreza, com capacidade de executar tarefas com velocidade e perfeição. Embutida nessa percepção está a noção de qualificação tácita, entendida como menor valorização do conhecimento formal em favor da experiência subjetiva, muito difícil sua transmissão por meio de linguagem explícita e formalizada. Este conhecimento está 
vinculado à vivência concreta de um trabalhador particular numa situação específica, como conhecedor único das idiossincrasias próprias ao equipamento que conduz ou opera (Castro, 1994; Gorz, 1989).

Esta relação entre qualificação e repetição de tarefas aparece desenvolvida em Marx (1988) ao definir qualificação como o processo exacerbado de redução da força de trabalho a uma única tarefa, de especialização. É tomado como um conjunto de condições físicas e mentais que compõe a força de trabalho dispendida em atividades voltadas para a produção de valores de troca. Sendo assim, a capacidade de trabalho é condição fundamental da produção capitalista, uma vez que representa a possibilidade de obtenção de um valor excedente, a mais-valia. Na esteira do taylorismo, qualificado é sinônimo de parcelado.

\section{A QUALIFICAÇÃO POLIVALENTE E POLITÉCNICA}

A qualificação também pode ser abordada em termos de polivalência ou politecnia. A polivalência significa trabalho mais variado, com certa abertura quanto à possibilidade de administração do tempo pelo trabalhador, não implicando necessariamente mudança qualitativa das tarefas (Machado, 1994). Nesta perspectiva, mesmo se tratando de equipamentos complexos, polivalência está longe de ser apreendida como intelectualização do trabalho, uma vez que está baseada em tarefas diversificadas, porém rotineiras. É suficiente, para ser um trabalhador polivalente, o recurso aos conhecimentos empíricos disponíveis, permanecendo a ciência como algo que lhe é exterior e estranho.

O trabalhador polivalente adquire conhecimento prático e assume cada vez mais funções rotineiras dentro da organização, intensificando seu trabalho, adicionando mais tarefas no mesmo período de tempo sem que haja mudança, necessariamente, profissional em termos qualitativos. Este trabalhador se torna capaz de "preparar a máquina, decidir sobre a seqüência de atividades a serem feitas, diagnosticar falhas no processo produtivo e agir sobre elas, prevenir produção fora da especificação etc.” (Dieese, 1994, p. 167), mas nada além dessa repetição sistemática de tarefas.

Esta situação pode ser observada após a informatização do sistema de atendimento nas unidades de saúde, quando os auxiliares de enfermagem passaram a executar tarefas que antes eram feitas por um profissional da área administrativa, gerando conflito e revelando, assim, um dos indicadores da precarização do trabalho:

“não sou auxiliar administrativo para fazer este serviço!” (Aux2, US-1, 28 Dez. 2000);

“esta não é minha função!”(Aux1, 22 Dez. 2000);

"o trabalho do auxiliar de enfermagem se tornou mais administrativo. $O$ número de atendimentos acaba forçando os atendentes a agilizar, mecanizar o atendimento. A pergunta: Como você está? Não revela mais a preocupação pelo estado do paciente. Mas a necessidade de obter este dado e preencher a ficha no computador. Sem este registro não se marca nada" (Aux2, 28 Dez. 2000).

Os profissionais admitem que antes da informatização não existia o referido conflito. Os depoimentos acima denotam, ainda, a falta de preparo destes profissionais para que assumam tarefas diferenciadas, pois, para exercer o trabalho polivalente o profissional deve possuir alguns requisitos comportamentais como: abertura, adaptação às mudanças, possibilidade de lidar com regras e normas em situações diferenciadas, curiosidade, vontade de aprender, motivação, iniciativa, atenção, responsabilidade etc. 
(Machado, 1994). E este preparo demanda treinamento adequado e tempo para que os profissionais se aperfeiçoem, buscando aproximar qualificação técnica de qualificação específica da função, uma vez que, esta qualificação técnica não se configura como parte da natureza do trabalho na saúde.

No caso de uma qualificação politécnica, estas exigências se redefinem com a incorporação de ingredientes como: discernimento e julgamento crítico; compreensão dos determinantes sociais, econômicos e políticos das ações a serem empreendidas; independência na avaliação das implicações das intervenções humanas frente a outras alternativas e finalidades, e criatividade no enfrentamento das contradições.

Poderíamos dizer, então, que a politecnia se inscreve na perspectiva de "continuidade" e "ruptura" com relação a polivalência e se apresenta como o "novo" em matéria de qualificação. Supõe que o trabalhador vá além do conhecimento específico na área da saúde, que seja capaz de atuar criticamente em algumas atividades e busque com autonomia os conhecimentos necessários ao seu progressivo aperfeiçoamento.

No entanto, no contrafluxo da politecnia, o que se percebe é que nas unidades de saúde o que está sendo exigido do profissional é a polivalência. A mudança no processo de atendimento (física e de gestão) é introduzida com o discurso de melhora qualitativa do trabalho e no atendimento à população, entretanto, nada mais é do que uma estratégia para obter mais produtividade, ou seja, adequar o atual número de profissionais ao aumento da demanda de usuários, reduzindo os custos de novas contratações. Na verdade não há ruptura, e sim intensificação da precariedade no trabalho do profissional e no atendimento à saúde.

Uma auxiliar de enfermagem ao ser questionada sobre a mudança no seu trabalho após tantas inovações respondeu da seguinte forma:

“... continua a mesma coisa. Inclusive, eu acho até que escravizou um pouco o funcionário, porque a maioria do pessoal que lida com a informática, geralmente tem uma carga horária reduzida. E a nossa carga horária continua oito horas" (Aux3, US-8, 09 Jan. 2001).

Este depoimento denota o sentimento do profissional de saúde com relação à sua formação específica, questionando a exigência da qualificação técnica imposta pelo computador.

\section{CONHECIMENTO COMO PILAR DA QUALIFICAÇÃO}

Na tradição marxista o conhecimento surge como um dos instrumentos utilizados pelo capital para maximizar a produtividade do trabalho e, conseqüentemente, obter maior mais-valia relativa.

Marx chamou de mais-valia relativa "a decorrente contração do tempo de trabalho necessário e da correspondente alteração na relação quantitativa entre ambas as partes componentes da jornada de trabalho" (Marx, 1988, p. 363). Considerando que a jornada de trabalho está dividida em trabalho socialmente necessário para pagamento da força de trabalho e trabalho excedente, a produção de mais valia relativa se dá pela redução do tempo de trabalho necessário, ou seja, o trabalhador deverá produzir em menos horas a mesma quantidade de meios de subsistência. Isto só é possível com o aumento da produtividade do trabalho. Por sua vez, a produtividade do trabalho exige modificação no processo, por meio de alterações no instrumental ou no método do trabalho, ou em ambos. 
Por muito tempo, a divisão social do trabalho e as inovações tecnológicas foram utilizadas como instrumentos necessários ao aumento da produtividade do trabalho. O trabalhador especializou-se, participando apenas da produção das partes, alienando-se do processo global da produção.

No setor de serviços não acontece bem assim. Ao contrário do que ocorre na indústria, a inovação tecnológica, por si só, não proporciona desempenho corporativo e nem lucratividade exacerbada (Andreassi, 2002). No setor de serviços em geral e na área da saúde, em especial, o que se destaca como fator fundamental são as habilidades e capacitações dos funcionários. O conhecimento, então, está associado diretamente à área da saúde.

A qualificação, portanto, é entendida neste trabalho, como a formação específica na área de saúde, equivocadamente caracterizada até mesmo pelos profissionais da saúde, como formação técnica. O conhecimento técnico, por sua vez, é entendido como a familiarização do profissional com a informática.

Os depoimentos abaixo mostram a influência negativa do sistema técnico sobre o sistema de saúde, indicadores da precarização do trabalho qualificado:

"se você entrar a fundo com esta pesquisa, o usuário vai dizer isso prá você. Que eles preferem falar com as enfermeiras, porque elas não têm computador na sala delas. 'E se a gente for falar com a pessoa ali, ah não dá... elas ficam no computador'. E a angústia deles é assim: a máquina é mais importante do que eu” (Enf3, US-12, 15 Out. 2001);

“a gente se sente assim... um pouco robotizada... já que às vezes... como numa pré-consulta, a gente pergunta pro paciente o que ele tem. Na época a gente conversava primeiro o que ele tem, perguntava: o que você tem? O neném tá tomando que leite? ... ia pesar, ia medir, e aí você ia conversando com a mãe ... ia orientando a mãe. Hoje, a gente abre a tela do computador dai pergunta: "o que é que tem o neném?"Daí a mãe vai falando e você vai digitando. Mas na realidade a mãe tá falando e você nem tá olhando prá mãe, você tá olhando prá tela" (Aux3, 09 Jan. 2001);

“... tem paciente que quer conversar... então às vezes a gente diz assim, que o nosso paciente é mais o computador do que o próprio paciente [risadinhas nervosas]" (Aux8, US-20, 25 Out. 2001);

"no começo eles reclamavam. Chegavam a dizer que a gente tava brincando naquela máquina e não dava bola prá eles. E bem no começo que é mais difícil, você fica ali... então eles diziam: 'vocês ficam brincando ai e não dão atenção prá gente"' (Aux5, US-18, 23 Out. 2001);

"no começo foi bem difícil [para o usuário]... Ficou complicado... porque existe uma adaptação, primeiro do funcionário, e o funcionário está se adaptando na frente do usuário... isso pro usuário foi ruim, então eles diziam assim: 'como é que mandam vocês, colocam vocês em área sem treinar, ai ficam se batendo'. Demorava muito o atendimento, fazia fila... então eles diziam que piorou porque...'estava piorando em vez de melhorar'; 'puseram o computador em vez de melhorar,"' (Enf2, US-5, 05 Out. 2001);

"porque você esquece, fica tão preso na parte burocrática [digitação dos dados] que o conteúdo da enfermagem, que é ver o todo do paciente, você já não tem mais... o paciente fala 
'olha parece que a gente é uma máquina aqui, tem que digitar prá gente sair"' (Enf3, US-12, 15 Out. 2001).

Muitos profissionais acabam por revelar que esta situação os preocupa. A introdução de um sistema informatizado alterando o processo de trabalho, com certeza deveria estar visando a uma melhoria nas condições de trabalho e atendimento aos usuários, mas ao que parece, o objetivo é otimizar o trabalho dos profissionais. A estrutura nas unidades mudou, mas a cultura social de apoio e priorização da saúde não. Buscou-se alterar o processo de trabalho para atender a uma demanda maior da população, mas não se investiu em aumento do número de profissionais nem na valorização dos que se dedicam a esta atividade.

Com a introdução do sistema informatizado houve aumento da produtividade em termos quantitativos, pois o número de atendimentos registrados aumentou (ver Tabela 1 anexo A). $\mathrm{O}$ aumento pode ser justificado tanto pela facilidade de controle e manutenção dos registros de atendimento na recepção das unidades, como, também, pelo aumento da área de abrangência da maioria das unidades do município. Não significa somente que com a informatização o número de pessoas atendidas pelas unidades aumentou, não mesmo. Este aumento pode ser melhor explicado pela nova gestão do processo de atendimento, pois após a informatização, toda e qualquer pessoa que chega na unidade, seja para marcar consulta, para pegar medicação ou para medir a pressão arterial, tem sua demanda registrada sistematicamente pelo computador. Desta forma, o número de registros nas unidades aumentou consideravelmente, pois anteriormente não se tinha registro e controle de todos os procedimentos realizados.

Os depoimentos que seguem reforçam o raciocínio de que, no setor da saúde, a inovação por si mesma não determina aumento de produtividade em termos quantitativos nem qualitativos:

"nem o número de consultas aumentou, nem o número de médicos. Não dá para aumentar as consultas porque já está no limite” (Aux4, 09 Jan. 2001);

[para melhorar precisa] "aumentar os médicos, porque têm poucos médicos, poucos especialistas...” (Aux5, US-18, 23 Out. 2001);

"a gente está com problemas porque não temos médicos. Então a gente tem muito mais usuário do que médicos na Unidade. Os pacientes se obrigam a vir mais cedo prá conseguir consulta" (Aux7, US-19, 24 Out. 2001);

“com a redução de pessoal, com a informatização se perdeu muito...” (Aux2, 28 Dez. 2000);

"então, por ter menos médico agora, os auxiliares estão [em] escala meio apertadinha... quando o médico está atendendo fica corrido, cada um tem seu lugarzinho... Teve uma época que nós éramos em quatorze, sempre ficavam dois em cada setor. Agora é um só por setor" (Aux4, 09 Jan. 2001);

"com o sistema informatizado você tem a tua agenda fechada... e você tem que ter os dezesseis atendimentos... eu acho que é pouco, eu acho que tinha que rever o tempo de atendimento na Unidade. Se você quer um serviço de qualidade, se você quer um atendimento minimamente razoável com o paciente, você não pode reduzir o tempo, você não tem como atender em menos tempo" (Med1, US-13, 16 Out. 2001). 
As declarações mostram que somente a inovação tecnológica não proporciona maior produtividade, especificamente, no setor de saúde. Seriam necessários investimentos em número de profissionais, incentivos salariais e suporte estrutural capazes de dar realmente importância tanto ao profissional quanto ao usuário/paciente. A percepção de que faltam médicos no setor de saúde torna visível que a produtividade do setor depende mais de profissionais capacitados em termos específicos do que das inovações tecnológicas.

No entanto, cumpre lembrar que da mesma forma que o capital físico, o capital humano também se deprecia. Demo (1999) afirma que o maior problema da depreciação do capital humano não é o processo físico da idade, mas a rapidez com que o conhecimento específico - aqui no caso, na saúde - e a tecnologia se tornam obsoletos. À medida que o desenvolvimento dos novos conhecimentos e novas tecnologias se aceleram, torna-se mais difícil e penoso para o trabalhador experiente da "sociedade do conhecimento" manter-se atualizado em seu campo de atuação.

Portanto, uma solução para que os trabalhadores mantenham suas habilidades e conhecimentos, atuando efetivamente no mercado de trabalho é o comprometimento com um aprendizado contínuo.

Neste sentido, algumas declarações feitas pelos profissionais de saúde contrariam os discursos "bem intencionados" em torno da formação continuada neste setor:

"no começo foi muito complicado, foi difícil... a equipe toda passou por um treinamento prévio, mas foi um treinamento muito rápido, se não me engano uma semana, três dias... E muita gente não tinha nem conhecimento do computador e isso dificultou muito..." (Enf5, US18, 23 Out. 2001);

“... o nosso treinamento foi mínimo, foram três dias só” (Aux4, 09 Jan. 2001);

"eu acho assim que a gente devia ter um treinamento melhor porque ainda tem coisas que a gente se perde. Mesmo que a gente tenha auxílio” (Aux8, US-20, 25 Out. 2001);

"o curso de treinamento foi muito rápido; o computador para mim era como uma nave de extraterrestres... 'foi um parto' - é muita coisa; tinha medo”' (Aux., US-28, 08 Nov. 2001);

"o treinamento foi só no início, os funcionários novos na Unidade estão aprendendo com os colegas que já sabem pouco” (Aux., US-14, 17 Out. 2001).

Como se percebe, os treinamentos muito rápidos revelam que há um abismo entre a prática e a teoria. Se a teoria fala em treinamento contínuo, os depoimentos mostram o contrário, uma vez que foram exíguos ou, em alguns casos, inexistentes.

Os dados revelam que, ao contrário da teoria de Demo, no setor de saúde os investimentos em conhecimento técnico e específicos foram praticamente nulos. Neste sentido o setor está no contrafluxo daquilo que Demo chama "sociedade do conhecimento", uma vez que prioriza mais o condicionamento técnico do profissional do que propriamente conhecimento na perspectiva emancipatória advogada por Demo. 


\section{IMPACTOS DA TECNOLOGIA INFORMACIONAL SOBRE A QUALIFICAÇÃO}

Os impactos da tecnologia informacional computadorizada na qualificação específica na saúde, sob o ponto de vista dos próprios profissionais, pode ser observada na Tabela 2 (Ver anexo B). Os dados mostram que $72,8 \%$ dos profissionais de saúde participantes da pesquisa concordam que para exercer sua função com o sistema informatizado é preciso mais habilidade manual.

Muitos desses profissionais nunca haviam manuseado um computador antes, como relatado nos depoimentos abaixo:

"o grande entrave foi esta dificuldade com o teclado e não ser preparada para tal" (Med, US-20, 25 Out. 2001);

"sentiu-se mal no começo; foi taxada por não atender o número mínimo de pacientes. Já com dificuldades pela idade, o computador emperrava, travava, a impressora tinha problemas... os avaliadores diziam que ela não atendia bem [olhos se encheram de lágrimas] com o computador em bom estado conseguiu conciliar o trabalho...” (Med, US-11, 11 Out. 2001);

"eu tenho muita dificuldade em digitar [sente-se mal] insegurança..." (Med, US-20, 25 Out. 2001);

“eu não sabia mexer com o mouse...” (Aux, US-20, 25 Out. 2001);

"eu acho que teria sido importante primeiro dar atenção à adaptação do indivíduo à tecnologia [interação da pessoa à máquina] para depois informatizar. Foi tudo muito jogado e pegou muita gente sem preparo. Os mais novos puderam acompanhar bem, mas os profissionais que estão a 10, 15, 20 anos no exercício da função não foram preparados para assimilar esta mudança; há a limitação manual também..." (Med, US-19, 24 Out. 2001).

O próximo relato denota a preocupação de um profissional médico com o andamento do trabalho nas Unidades:

"o pessoal que tem dificuldade prá manejar o sistema realmente não se sente muito à vontade e ai dificulta o trabalho" (Med1, US-13, 16 Out. 2001).

A pouca habilidade manual no computador dificulta o exercício da função específica do profissional, gerando reclamações, atrasos e tumultos.

Os dados da Tabela 2 (ver anexo B), também revelam que 77\% dos profissionais de saúde concordam que é preciso mais atenção no trabalho após a introdução do computador. Atenção esta não em relação ao exercício da profissão, mas do ponto de vista técnico.

“agora sim [precisa mais atenção no trabalho]. Porque senão... se você não tiver atenção... você perde o paciente na tela, ou a gente marca em outra atividade e na hora que ele vem [usuário] o nome não está lá [na tela]” (Aux8, US-20, 25 Out. 2001);

“... você tem que ficar cuidando da tela [mais atenção]” (Aux8, US-20, 25 Out. 2001);

“o sistema tira a atenção; o tempo é curto" (Med, US-30, 19 Nov. 2001). 
A atenção do profissional desvia-se da natureza do seu trabalho, antes do paciente, vem a tela do computador. O trabalho, assim, sofre a interferência direta da máquina.

Dos profissionais, quando questionados sobre a necessidade de se ter maior responsabilidade no trabalho para exercer a sua função, foram obtidas respostas muito próximas de $50 \%$, conforme Tabela 2 (ver anexo B). A explicação se dá pelo entendimento da questão. Os profissionais que concordaram com a afirmação, assim o fizeram no sentido do conhecimento técnico. É necessário que o profissional seja responsável e não deixe passar nenhum dado despercebido, não deixe de alimentar os dados exigidos pelo sistema para não bloquear o trabalho. Denota receio do controle exercido e favorecido pelo computador. Por sua vez, os profissionais que discordaram da afirmação, assim o fizeram no sentido do conhecimento específico da área saúde. Estão seguros em afirmar que a responsabilidade do profissional da saúde é a mesma com ou sem computador.

Os dados da Tabela 2 (ver anexo B), revelam que 70,2\% dos profissionais discordam da afirmação de que é necessária maior escolaridade para exercer sua função com o computador. No entanto, 82,3\% concordam que é preciso mais treinamento com o computador. Conforme discutido anteriormente, a falta de treinamento intensifica a precarização do trabalho na saúde. O profissional perde muito tempo manuseando a "máquina", tentando decifrar seus segredos e dominar a lógica que está por trás do equipamento, enquanto o paciente aguarda sua vez de ser alvo do olhar do profissional.

Outro dado interessante, diante do exposto, é que 70,6\% dos profissionais discordam de que é preciso muita experiência para trabalhar com o sistema informatizado. Muitos acreditam que a partir do momento que eles dominarem a "máquina" tudo será resolvido. Mas enquanto isso não acontece, eles procuram driblar as dificuldades e se acostumar às rotinas técnicas impostas pelo sistema. Os profissionais, portanto, estão sendo condicionados ao computador, que é muito diferente de dominar e entender o sistema que operam.

Dentre os profissionais de saúde, 94\% discordam da afirmação de que o sistema informatizado tornou o seu conhecimento de enfermagem ou da área médica em geral, menos necessário do que no sistema antigo. Este dado revela que o sistema técnico é visto pelos profissionais como um sistema à parte do exercício da sua função. Não há qualquer homogeneidade com o trabalho da saúde. Os profissionais, ao responderem a esta questão, não conseguiram conter o espanto diante da própria pergunta, o “DISCORDO” foi sonoro e contundente. Muitos justificaram dizendo que:

"a informatização não tem nada a ver com o nosso trabalho de enfermagem” (Aux, US-14, 17 Out. 2001);

"questiona muito a interferência do computador no seu trabalho - vê o trabalho da enfermagem separado da informática; $O$ trabalho da enfermagem é a orientação que está totalmente esquecida. O trabalho de prevenção é mais importante e está esquecido. Perde-se muito tempo com telas, consultas..." (Aux, US-21, 26 Out. 2001).

Trata-se de uma qualificação que orienta o profissional muito mais para servir à máquina do que ao paciente, caracterizando assim, "uma inversão da relação do homem com a máquina" (Pagés, 1987, p. 108). Neste processo, do ponto de vista da saúde, trata-se de uma qualificação às avessas, pois desqualifica o profissional no que tange à relação com o paciente. Isto não significa que haja perda absoluta de qualificação, mas uma perda relativa, ligada ao papel cada vez menos importante que o trabalhador tem em relação ao das máquinas automatizadas e integradas no processo produtivo. 


\section{CONSIDERAÇÕES FINAIS}

Este trabalho é um chamamento modesto a uma redefinição do conceito de qualificação. É um pleito, uma reivindicação que aponta os limites da noção clássica da qualificação que é funcional a uma racionalidade instrumental. Significa afirmar que aceitar a qualificação da forma como está posta, inclusive no entendimento dos profissionais da área, no seu sentido estrito, significa elaborar uma análise resignada das experiências associativas, que não é o caso.

Verifica-se que com a introdução de um sistema informatizado, não há melhoria nas condições de trabalho e atendimento aos usuários, o que se evidencia é cobrança pela otimização do trabalho dos profissionais. Um exemplo disso, é que a estrutura nas unidades mudou, mas a cultura social de apoio e priorização da saúde não. Buscou-se alterar o processo de trabalho para atender a uma demanda maior da população, mas não se investiu em aumento do número de profissionais nem na valorização dos que se dedicam a esta atividade.

Infere-se, portanto, que no setor da saúde pesquisado, a inovação por si mesma não determina aumento de produtividade em termos quantitativos nem qualitativos.

Os dados obtidos revelam que no setor de saúde os investimentos em conhecimento técnico e específicos foram praticamente nulos. Neste sentido o setor está no contra-fluxo daquilo que Demo chama "sociedade do conhecimento", uma vez que prioriza mais o condicionamento técnico do profissional do que propriamente conhecimento na perspectiva emancipatória.

Ao que parece, as experiências concretas de qualificação no setor de saúde podem ser caracterizadas como expressões do behaviorismo: "qualificação" = "condicionamento", buscando com isso, a otimização dos serviços prestados.

Da mesma forma, a pesquisa identifica alguns indicadores da precarização do trabalho. A atenção do profissional, por exemplo, se desvia da natureza do seu trabalho, pois antes do paciente, vem a tela do computador. Do ponto de vista dos profissionais, o trabalho sofre a interferência direta da máquina.

Outro aspecto sobre a qualificação para o trabalho informatizado, diz respeito à habilidade manual para o exercício da função específica do profissional. A falta de habilidade e familiaridade dos profissionais com o computador acaba por bloquear o andamento do trabalho, gerando reclamações e atrasos.

Verifica-se, também, que os profissionais demandam mais treinamento técnico para lidar com o computador e com o sistema informacional. Pois a falta de treinamento intensifica a precarização do trabalho na saúde porque o profissional perde mais tempo manuseando a "máquina", tentando decifrar seus segredos e dominar a lógica que está por trás do equipamento, enquanto o paciente aguarda sua vez de ser alvo do olhar do profissional.

A aproximação do sistema técnico informacional do sistema de saúde tende a precarizar o profissional de saúde à medida que exige conhecimento além da natureza do seu trabalho, obrigando-o a se familiarizar com um instrumento estranho ao seu próprio trabalho.

Ao ficar mais tempo familiarizando-se, adaptando-se, dando mais atenção à máquina, a tendência é comprometer, degenerar as relações entre os homens. Até porque, não tem como pensar em saúde sem pensar nas relações sociais entre homens. 
Ao invés de uma relação de equilíbrio entre saúde e tecnologia informacional, acontece o contrário, o domínio da racionalidade instrumental, técnica, sobre a subjetividade humana.

Ao se fazer a crítica da racionalidade instrumental não significa deixar de considerar sua importância para qualquer organização. O que se questiona é o seu predomínio apenas.

Finalmente, na perspectiva dialética a idéia de construção perene dos conceitos e do conhecimento é uma realidade que se materializa. Ao redefinir, a partir das práticas dos profissionais da saúde, o conceito de qualificação, o presente artigo esboça sua principal originalidade, permite deslocar o conceito de qualificação de um domínio instrumental para um domínio substantivo.

\section{NOTAS}

Mais detalhes ver Shimazaki, Maria Emi et ali. Acolhimento Solidário - a saúde de braços abertos. In: Ducci, Luciano et ali. (Orgs.) Curitiba: a saúde de braços abertos. Rio de Janeiro : CEBES, 2001.

2 Para maiores informações sobre a concepção e implantação do prontuário eletrônico ver Schneider, Ana Luiza et ali. Informatização dos processos de trabalho em Curitiba: a história do cartão Qualidade-Saúde de Curitiba. In: Ducci, Luciano e outros (Orgs.) Curitiba: a saúde de braços abertos. Rio de Janeiro : CEBES, 2001. p. 43-77;

3 Este é o número de profissionais de saúde no terceiro trimestre de 2001, distribuídos em 105 Unidades de Saúde do Município. Pelas dificuldades em se ter acesso às informações sobre Recursos Humanos na Secretaria Municipal de Saúde e pela rotatividade destes profissionais este número não é exato.

\section{REFERÊNCIAS}

ANDREASSI, Tales. Inovação em serviços: desafios e oportunidades. Jornal da SBPC, 25 jan. 2002.

ASSOCIAÇÃO BRASILEIRA DE NORMAS TÉCNICAS. NBR 6023: referências - elaboração. Rio de Janeiro, 2000.

ASSOCIAÇÃO BRASILEIRA DE NORMAS TÉCNICAS. NBR 10520: citações em documentos apresentação. Rio de Janeiro, 2001.

ASSOCIAÇÃO BRASILEIRA DE NORMAS TÉCNICAS. NBR 14724: informação e documentação - trabalhos acadêmicos - apresentação. Rio de Janeiro, 2001.

BARDIN, Laurence. Análise de Conteúdo. Lisboa : Edições 70, 1979.

BRAVERMAN, Harry. Trabalho e capital monopolista. 3ed. Rio de Janeiro : Guanabara, 1987.

CASTRO, Nadya A. Organizações do trabalho, qualificação e controle na indústria moderna. Trabalho e educação - Coletânea da Conferência Brasileira de Educação - C.B.E. $2^{a}$ ed. São Paulo : Papirus, 1994. 
CORIAT, Benjamin. Automação programável: novas formas e conceitos de organização da produção. In.: SCHIMTZ, H; CARVALHO, R. Q. Automação, competitividade e trabalho: a experiência internacional. São Paulo : Hucitec, 1988.

DELLAGNELO, Eloise L.; MACHADO-DA-SILVA, Clóvis L. O modelo burocrático de organizações e as novas formas organizacionais: ruptura ou flexibilização? (Texto impresso).

DEMO, Pedro. Conhecimento como vantagem comparativa. Revista da FAE, Curitiba, v. 2, n. 1, p. 1-11, jan./abr. 1999.

DIEESE. Trabalho e reestruturação produtiva: 10 anos de linha de produção/DIEESE. São Paulo : DIEESE, 1994.

FARIA, José Henrique de. Comissões de fábrica: poder e trabalho nas unidades produtivas. Curitiba : Criar, 1987.

GORZ, André. O despotismo de fábrica e suas conseqüências. Crítica da divisão do trabalho. Org. e Apres. André Gorz. 2a ed. São Paulo: Martins Fontes, 1989.

HARNECKER, Marta. Tornar possível o impossível: a esquerda no limiar do século XXI. São Paulo : Paz e Terra, 2000.

HARVEY, David. Condição pós-moderna. São Paulo : Loyola, 1993.

LEITE, Marcia de Paula. Reestruturação produtiva, novas tecnologias e novas formas de gestão da mão-de-obra. In : O mundo do trabalho : crise e mudança no final do século. OLIVEIRA, C. A. B. de, et alli (Orgs.), São Paulo : Scritta/Cesit/Unicamp, 1994.

LOJKINE, Jean. A revolução informacional. São Paulo : Cortez, 1995.

MACHADO, Lucília R. de S. Mudanças tecnológicas e a educação da classe trabalhadora. Trabalho e educação - Coletânea da Conferência Brasileira de Educação - C.B.E. 2a ed. São Paulo : Papirus, 1994.

MALHOTRA, Naresh K. Pesquisa de Marketing : uma orientação aplicada. 3ed. Porto Alegre : Bookman, 2001.

MARX, Karl. O capital: crítica da economia política. 12a ed. Rio de Janeiro : Bertrand Brasil S. A., 1988. (Livro I, Volume I)

PAGÉS, Max et al. O poder das organizações. São Paulo : Atlas, 1987.

SCHNEIDER, Ana Luiza et ali. Informatização dos processos de trabalho em Curitiba - a história do Cartão Qualidade-Saúde de Curitiba. In: Ducci, Luciano et ali. (Orgs.) Curitiba: a saúde de braços abertos. Rio de Janeiro : CEBES, 2001.

SHIMAZAKI, Maria Emi. Et al. Acolhimento Solidário : a saúde de braços abertos. In: Ducci, Luciano e outros (Orgs.) Curitiba: a saúde de braços abertos. Rio de Janeiro : CEBES, 2001. p. 63-77. 


\section{ANEXO A}

TABELA 1 - UNIDADES DE SAÚDE INFORMATIZADAS E POPULAÇÃO ATENDIDA- 1999-2001

\begin{tabular}{|l|c|c|c|}
\hline \multicolumn{1}{|c|}{ INDICADORES } & $\mathbf{1 9 9 9}$ & $\mathbf{2 0 0 0}$ & $\mathbf{2 0 0 1}$ * \\
\hline Unidades de saúde informatizadas & 36 & 86 & 38 \\
\hline Famílias cadastradas & 87.570 & 303.264 & 1.228 .155 \\
\hline Usuários cadastrados & 218.925 & 804.569 & $* *$ \\
\hline Cartões distribuídos & 45.904 & 734.990 & \\
\hline
\end{tabular}

Fonte: Assessoria de Informação - SMS - Comparativo anual de atividades e Relatório $3^{\circ}$ Trimestre - SMS

* Dados referentes ao $3^{\circ}$ Trimestre de 2001.

** Dado ainda não disponível.

\section{ANEXO B}

TABELA 2 - TECNOLOGIA E QUALIFICAÇÃO : A PERSPECTIVA DO PROFISSIONAL DE SAÚdE

\begin{tabular}{|lcc|}
\hline QUALIFICAÇÃO & $\begin{array}{c}\text { DISCORDO } \\
\mathbf{\%}\end{array}$ & $\begin{array}{c}\text { CONCORDO } \\
\mathbf{\%}\end{array}$ \\
\hline $\begin{array}{l}\text { Para trabalhar com o sistema informatizado é preciso mais habilidade } \\
\text { manual. }\end{array}$ & 27,2 & 72,8 \\
\hline É preciso mais atenção no trabalho. & 23 & 77 \\
\hline É preciso maior responsabilidade. & 50,6 & 49,4 \\
\hline É preciso maior nível de escolaridade. & 70,2 & 29,8 \\
\hline É preciso mais treinamento pessoal (com o computador). & 17,7 & 82,3 \\
\hline É preciso muita experiência. & 70,6 & 29,4 \\
\hline $\begin{array}{l}\text { O sistema informatizado tornou o seu conhecimento de enfermagem ou da } \\
\text { área médica em geral, menos necessário do que no sistema antigo. }\end{array}$ & 94 \\
\hline $\begin{array}{l}\text { A função delegada não aumenta a capacidade operacional da equipe de } \\
\text { enfermagem. }\end{array}$ & 73,2 & 6 \\
\hline $\begin{array}{l}\text { As atividades delegadas não propiciam um atendimento mais amplo e de } \\
\text { resultado para o usuário. }\end{array}$ & 81,1 & 18,9 \\
\hline
\end{tabular}

Fonte: Dados primários da pesquisa 